\title{
Study on Silybum marianum Seed through Fatty Acids Comparison, Peroxide Tests, Refractive Index and Oil Percentage
}

\author{
Iman Nasrollahi ${ }^{1 *}$, Ebrahim Talebi ${ }^{1}$, Zahra Nemati ${ }^{2}$
}

Iman Nasrollahi ${ }^{1 *}$, Ebrahim Talebi ${ }^{1}$, Zahra Nemati ${ }^{2}$

'Young Researchers and Elite Club, Darab Branch, Islamic Azad University, Darab, Fars, Iran

${ }^{2}$ Shiraz branch Islamic Azad university, shiraz, Fars, IRAN.

\section{Correspondence}

Iman Nasrollahi, Young Researchers and Elite Club, Darab Branch, Islamic Azad University, Darab, Fars, IRAN.

Mobile Number: +98-9394779695

E-Mail: iman.nasrollahi.67@gmail.com

DOI : 10.5530/pj.2016.6.13

Article Available online

http://www.phcogj.com/v8/i6

\section{Copyright}

(C) 2016 Phcog. Net. This is an openaccess article distributed under the terms of the Creative Commons Attribution 4.0 International license.

\begin{abstract}
In this study, milk thistle seeds were collected from four regions of Iran (Ahvaz, Lorestan, Kazeroon and Zarghan). The oil extracted from seeds of plant using n-hexane solvent extraction soxhlet. The extracted oil was analyzed by gas chromatography and fatty acids were identified in all four samples. In all four samples, the oil refractive index of Milk thistle oil fatty acids vis. Linoleic acid, Oleic acid, Palmitic acid was evaluated. The Peroxide test and determination of oil percentage was performed in Milk thistle seed oil.
\end{abstract}

Key words: Milk Thistle, Oil, Extraction, Peroxide, Fatty Acids

\section{INTRODUCTION}

Fatty acids play an important role in human nutrition. Particularly, unsaturated fatty acids are associated with a reduced risk of developing cardiovascular disease, inflammatory and autoimmune diseases such as asthma, Crohn's disease, arthritis, and certain cancers, including colon, breast and prostate cancers. ${ }^{1}$ Nutritional deficiencies or disturbances can depend on different factors and cause a variety of diseases. ${ }^{2}$

Silybum marianum (family: Compositae) is an annual or biennial plant, native to the Mediterranean area and now it known to have spread to other warm and dry regions. ${ }^{3}$ This plant also grows in many regions in Iran. Extracts from the mature milk thistle seeds are used as medical remedies for liver disease, liver cirrhosis for prevent liver cancer . ${ }^{4,5}$

This particular plant which can reach heights of two meters has dark shiny green leaves with spiny scalloped edges, purple to reddish purple flowers, and an indeterminate growth habit that results in staggered flowering and maturity. ${ }^{6}$ Milk thistle is a serious weed in many areas of North and South America, Africa, Australasia, and the Middle East .?

The pharmaceutical compound of milk thistle is derived from its fruits, which are achene's (Fructus silybi mariani). In their dry pericarp and seed coat the plant accumulates a group of flavonolignans commonly referred to as silymarin. ${ }^{8}$ Milk thistle (Silybum marianum) is an herb that is increasingly used in oncology research and treatment settings. Historically, it has been used to treat liver and biliary disorders and has been used in detoxification and cleansing protocols. ${ }^{9}$ The aim of this study was investigation on Silybum marianum oil plant.

\section{MATERIALS AND METHODS}

\section{Materials}

Milk thistle seed were collected from four regions in Iran, (Ahvaz, Lorestan, Kazeroon and Zarghan (Fars- Iran) in July 2015. After collecting the seeds of milk thistle the seeds were dried and prepared for extraction of oil (Figure 1).

Oleic acid composition of oil was identified by gas chromatography, also measure the refractive index, determining the percentage of oil, determining the peroxide value; Milk thistle seed for oils was performed.

\section{Oil extraction}

The seeds oil was extracted using Soxhlet. ${ }^{10,11}$ The seeds were dried from the Milk thistle plant. 30 grams of milk thistle seed were powder and then the powder, cartouche putinto Soxhlet, special balloons solvent and $500 \mathrm{ml}$ of $\mathrm{n}$-hexane solvent added into Soxhlet in $70^{\circ}$ a period of 8 hours. Then solvent flask containing the milk thistle seed oil was separated by Rotary and the weight of oil was determined. Grams of oil obtained from the dried plants are used for oil extraction subtraction. Methyl esters are identified using gas chromatography.

Analysis of fatty acid methyl esters by GC The FAMES were analyzed by GC according to the method described by Azadmard-Damirchi and Dutta. ${ }^{12}$ The GC instrument was equipped with a flame ionization detector and a split/split less injector. A film thickness fused-silica capillary column BPX70 (SGE, Austin, TX, USA) was used for analysis. Injector and detector temperatures were 230 and 


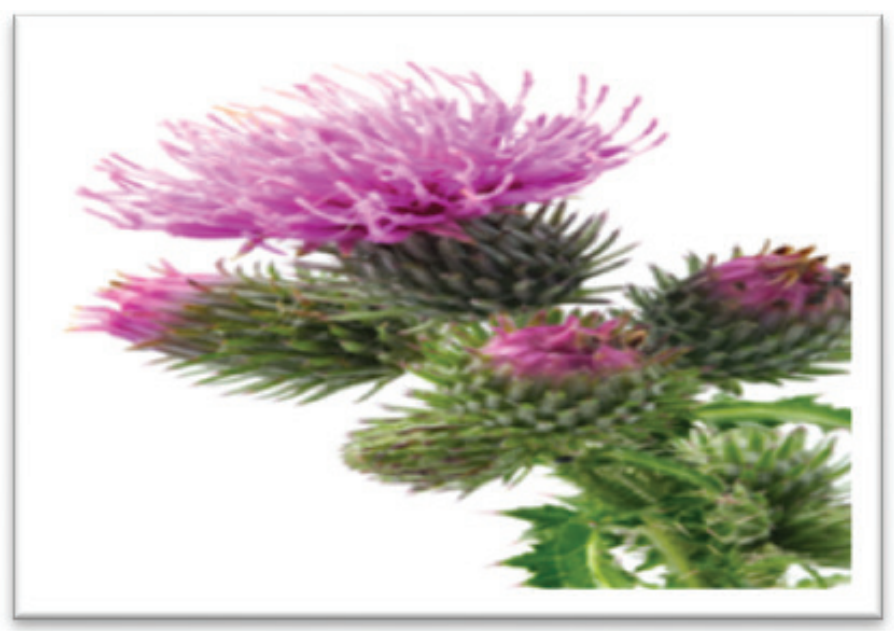

Figure 1: Milk thistle plant

$250{ }^{\circ} \mathrm{C}$, respectively. Oven conditions were $158^{\circ} \mathrm{C}$ increased to $220^{\circ} \mathrm{C}$ at a rate of $2{ }^{\circ} \mathrm{C} / \mathrm{min}$ and maintained for 5 minutes.

Helium was used as the carrier gas and nitrogen as the make-up gas at a flow rate of $30 \mathrm{ml} / \mathrm{min}$. The FAMES were identified by comparison of their retention times with standard FAMES and the peak areas reported as a percentage of the total fatty acids. ${ }^{13}$

\section{Determination of oil peroxide}

Peroxide value (PV) was determined according to the AOAC method. ${ }^{14}$ About $5 \mathrm{~g}$ of oil was weighed into a $250 \mathrm{~mL}$ flask. Previously prepared acetic acid/chloroform $(\mathrm{CHCl} 3)$ solution $(30 \mathrm{~mL})$, saturated potassium iodide $(0.5 \mathrm{~mL})$ and distilled water $(30 \mathrm{~mL})$ were added with occasional shaking. The mixture was titrated with $0.05 \mathrm{~mol} \mathrm{~L}-1 \mathrm{Na} 2 \mathrm{~S} 2 \mathrm{O} 3$ with vigorous shaking; $0.5 \mathrm{~mL}$ of $10 \mathrm{~mL} \mathrm{~L}-1$ starch solution was added a dtitration was continued with vigorous shaking, to release all iodine from the $\mathrm{CHCl} 3$ layer, until the blue color just disappeared. PV was calculated using this equation. ${ }^{15}$

$$
\mathrm{PV}(\text { meq O2 kg-1 sample })=(S \times 2 M \times 1000) / m
$$

Where $\mathrm{S}(\mathrm{mL})$ is the volume of $\mathrm{Na} 2 \mathrm{~S} 2 \mathrm{O} 3$ consumed (blank corrected), $\mathrm{M}(\mathrm{mol} \mathrm{L}-1)$ is molarity of $\mathrm{Na} 2 \mathrm{~S} 2 \mathrm{O} 3$ and $\mathrm{m}(\mathrm{g})$ is the mass of the test sample. ${ }^{15}$

\section{Measure the refractive index}

A Metrohm 743 Rancimat (Metrohm AG, Herisau, Switzerland) was used for analysis of the oxidative stability index (OSI). The tests were done with $3 \mathrm{~g}$ oil sample at a $120^{\circ} \mathrm{C}$ temperature in airflow rate of $15 \mathrm{~L} \mathrm{~h}-1 .^{16}$

\section{Results and discussions}

The oil content and the fatty acid composition found in our experiments correspond well with previously published values. ${ }^{17-20}$ The climatic conditions and varieties grown greatly influence the oil and fatty acids content. ${ }^{20}$ Oil obtained from the seeds of milk thistle were analyzed with gas chromatography, and the composition of fatty acids in all four samples of milk thistle oil from the areas was prepared and identified (Table 1). The composition of fatty acids in plant oils contains Milk thistle was included C18:2, C18:1, C16:0. The Linoleic acid achieved from Milk thistle which collected from Lorestan and Ahvaz exhibited more amount compared with Kazeroon and Zarghan. Fatty acid composition of plants collected from Ahvaz, Lorestan, Kazeroon and Zarghan is shown in figure 1 to 4 , respectively.

\begin{tabular}{|c|c|c|c|c|c|}
\hline \multicolumn{2}{|c|}{ Fatty acid composition } & \multirow{2}{*}{$\begin{array}{c}\begin{array}{c}\text { Oil } \\
\text { sample } \\
\text { (Ahvaz) }\end{array} \\
8.55\end{array}$} & \multirow{2}{*}{$\begin{array}{c}\begin{array}{c}\text { Oil sample } \\
\text { (Lorestan) }\end{array} \\
8.36\end{array}$} & \multirow{2}{*}{$\begin{array}{c}\begin{array}{c}\text { Oil sample } \\
\text { (Kazeroon) }\end{array} \\
7.99\end{array}$} & \multirow{2}{*}{$\begin{array}{c}\begin{array}{c}\text { Oil } \\
\text { sample } \\
\text { (Zarghan) }\end{array} \\
9.26\end{array}$} \\
\hline $\mathrm{C} 16: 0$ & Palmitic acid & & & & \\
\hline C16:1 & Palmitoleic acid & --- & --- & --- & --- \\
\hline $\mathrm{C} 17: 1$ & margaric acid & --- & --- & --- & --- \\
\hline $\mathrm{C} 18: 0$ & Stearic acid & 5.609 & 7.72 & 5.607 & 5.01 \\
\hline C18:1 & Oleic acid & 28.68 & 35.85 & 28.54 & 30.42 \\
\hline $\mathrm{C} 18: 2$ & Linoleic acid & 54.65 & 43.57 & 54.71 & 52.78 \\
\hline $\mathrm{C} 18 ; 3$ & Linolenic acid & 2.50 & 4.48 & 3.13 & 2.51 \\
\hline C20:0 & arashidic acid & --- & --- & --- & --- \\
\hline C22:0 & Behenic acid & --- & --- & --- & --- \\
\hline
\end{tabular}

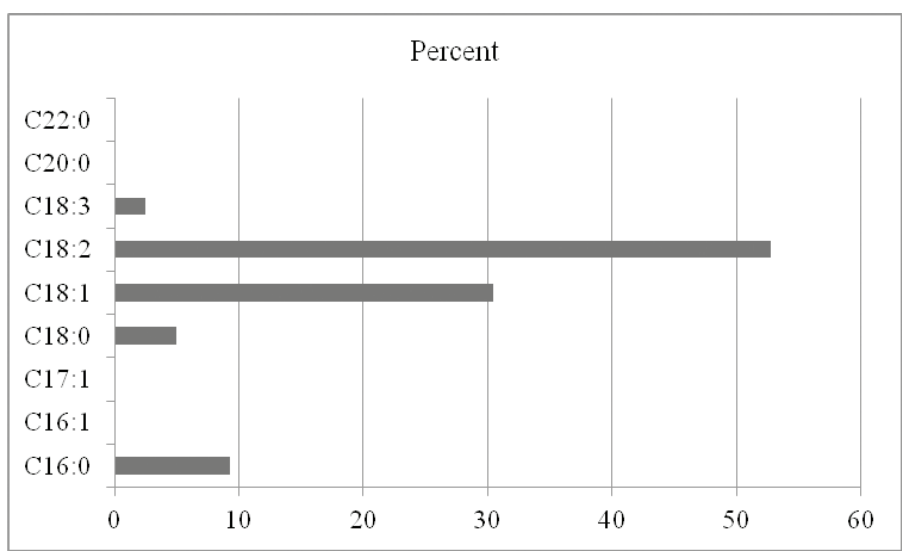

Figure 1: Milk thistle oil fatty acid composition extracted from Ahvaz

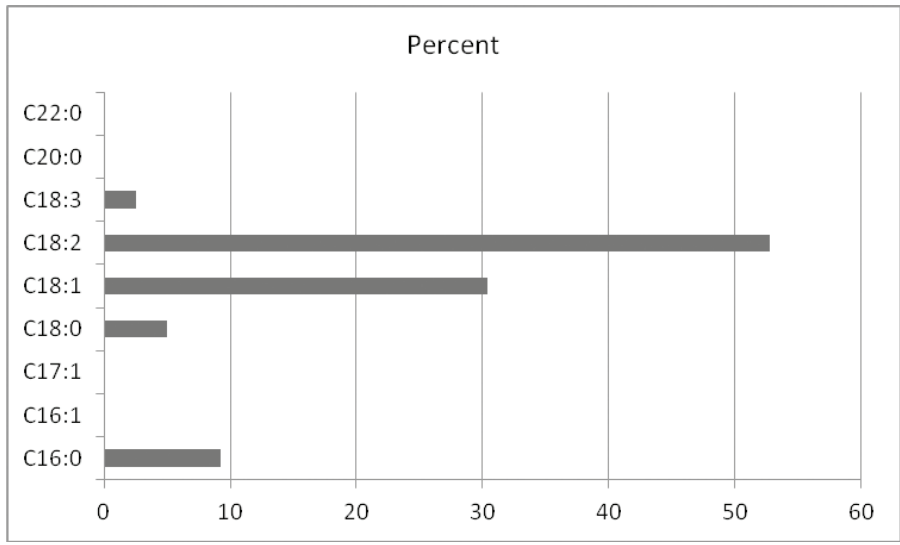

Figure 2: Milk thistle oil fatty acid composition extracted from Lorestan

\section{Oxidative stability}

Oxidative stability of oil for each four sample was performed. The results are shown in table 2. Results in this experiment showed a significant effect of weather conditions on the oxidation of the oil sample.

\section{Determine percentage of oil}

Percentage of oil was determined for each sample and the results are shown in table 3. The highest percent of oil content exhibited from Ahvaz.

\section{Refractive index}

Rancimat device used to measure the refractive index of the oil and the results are presented in bellow (Table 4). The less number of double bonds in samples revealed less refractive index and the samples with higher refractive index showed lower melting point and saturation. 


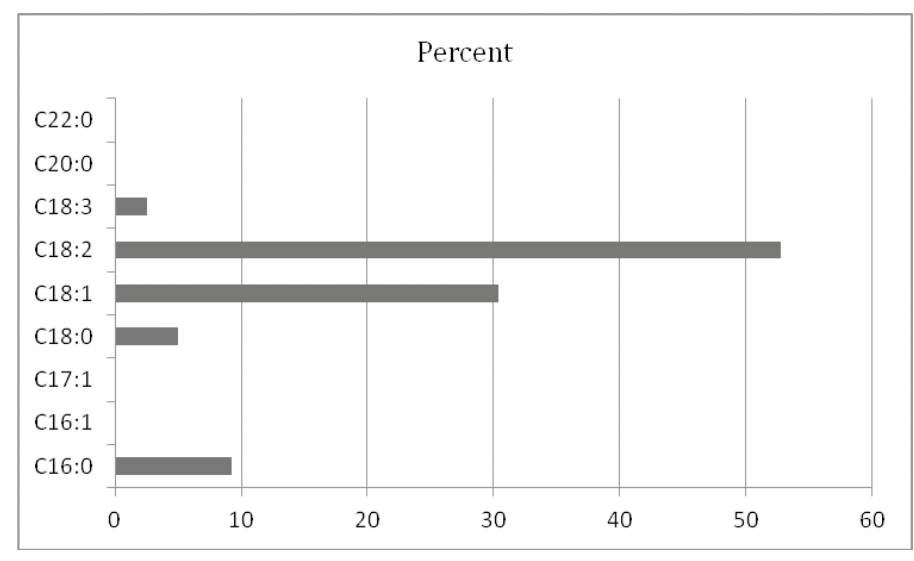

Figure 3: Milk thistle oil fatty acid composition extracted from Kazeroon

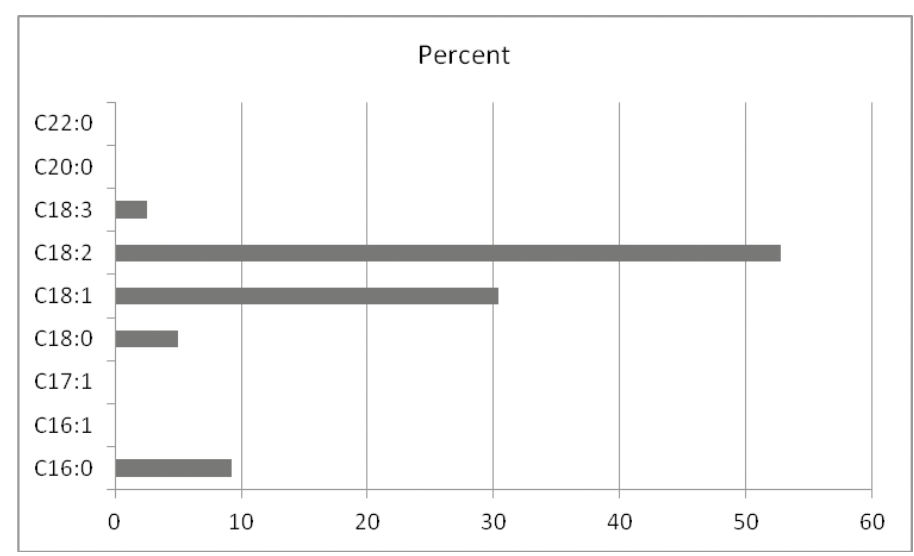

Figure 4: Milk thistle oil fatty acid composition extracted from Zarghan

Table 2: The oxidative value for Milk thistle seed oil

\begin{tabular}{cc}
\hline Sample oil & Oxidation value (pv) \\
\hline Oil sample (Ahvaz) & 0.51 \\
Oil sample (Lorestan) & 0.69 \\
Oil sample (Kazeroon) & 0.68 \\
Oil sample (Zarghan) & 0.57 \\
\hline
\end{tabular}

Table 3: Percentage of oil in samples

\begin{tabular}{cc}
\hline Sample oil & percentage of oil \\
\hline Oil sample (Ahvaz) & $25.61 \%$ \\
Oil sample (Lorestan) & $24.02 \%$ \\
Oil sample (Kazeroon) & $25.32 \%$ \\
Oil sample (Zarghan) & $21.28 \%$ \\
\hline
\end{tabular}

Table 4: Refractive index of the oil samples

\begin{tabular}{cc}
\hline Sample oil & Refractive index \\
\hline Oil sample (Ahvaz) & 1.4656 \\
Oil sample (Lorestan) & 1.46482 \\
Oil sample (Kazeroon) & 1.4656 \\
Oil sample (Zarghan) & 1.4651 \\
\hline
\end{tabular}

\section{ACKNOWLEGEMENT}

The first author wishes to express sincere thanks to Firoozabad branch, Islamic Azad University and Darab branch, Islamic Azad University for providing the funds. We wish to thankthe Chairman, Department of Animal Science, Darab branch, Islamic Azad University for extending the laboratory facilities to carry out the research work.

\section{CONFLICT OF INTEREST}

The authors declare no conflict of interest

\section{REFERENCES}

1. Simopoulus Ap. The importance of ratio of omega-6/ omega-3 essential fatty acids, Biomedical Pharmacotherap. 2002;56(8):365-79 .http://dx.doi.org/ 10.1016/S0753-3322(02)00253-6.

2. SCHIAVONE A, RIGHI F, QUARANTELLI A, BRUNI R, SERVENTI P, FUSARI A, Use of Silybum marianum fruit extract in broiler chicken nutrition: influence on performance and meat quality, Journal of Animal Physiology and Animal Nutrition. 2007;91(5-6):256-62.

3. Fang Li, Liuqing Yang, Ting Zhao, Jiangli Zhao, Yanmin Zou, Ye Zou, Xiangyang Wuc, Optimization of enzymatic pretreatment for n-hexane extraction of oil from Silybum marianum seeds using response surface methodology, Food and Bioproducts Processing .2012;90 (2):87-94 .http://dx.doi.org/10.1016/j. fbp.2011.02.010

4. Angeles S.M, Fernandez-Tarrago J, Purificacion C, Yeast extract and methyl jasmonate induced silymarin production in cell cultures of Silybum marianum (L.), Gaertner J. Biotechnology . 2005;119(1):60 -69 .http://dx.doi.org/10.1016/j. jbiotec.2005.06.012; PMid:16054261.

5. Ramasamy K, Agarwal R, Multitargeted therapy of cancer by silymarin, Cancer letters . 2008;269 (2) . 352-362.http://dx.doi.org/10.1016/j.canlet.2008.03.053 PMid:18472213 PMCid:PMC2612997.

6. Carrier DJ , Crowe T, Sokhansanj S, Wahab J, Barl B, Milk thistle, Silybum marianum (L.) Gaertn, Flower Head Development and Associated Marker Compound Profile, Journal of Herbs, Spices \& Medicinal Plants .2003;10(1):65-74

7. Holm L.G, Doll J, Holm E, Pancho J, Herberger J, World Weeds. Natural Histories and Distribution.Wiley, NewYork .1997.

8. Cappelletti EM, Caniato R, Silymarin localization in the fruit and seed of Silybummarianum (L.), Gaertn Herba Hungar .1984;23(1-2):53-66

9. Greenlee H, Abascal K, Yarnell, E. Ladas E, Clinical Applications of Silybum marianum in oncology, integrative cancer therapies . 2007;6(2):158-165.

10. Soxhlet F, Soxhletüber gewichtsanalytische Bestimmung des Milchfettes, Dingl Polyt. J. 1879;232:461-5.

11. CSN ENISO, Oilseeds: determination of oil content (reference method). ICS 67.200.20 (2009).

12. Azadmard-Damirchi S, Dutta P.C, Novel solid-phase extraction method to separate 4-desmethyl-, 4-monomethyl-, and 4, 40-dimethylsterols in vegetable oils, J. Chromatogr.2006; 1108(2):183 -187 .http://dx.doi.org/10.1016/j.chroma 2006.01.015; PMid:16445919.

13. Fathi-Achachlouei B, Azadmard-Damirchi S, Milk thistle seed oil constituents from different varieties grown in Iran , J. Am. Oil Chem. Soc.2009;86(7):643-9.

14. AOAC, Official Methods of Analysis( $16^{\text {th }}$ edn), Association of official analytical chemists, Washington, DC. 1999.

15. Jabri Karoui I, Dhifi W, Jemia M.B, Marzouk B, Thermal stability of corn oi flavoured with Thymus capitatus under heating and deep-frying conditions, J. Sci. Food Agric. 2011;91(5):927 -933 .http://dx.doi.org/10.1002/jsfa.4267; PMid:21384362.

16. Farhoosh R, Einafshar S, Sharayei $P$, The effect of commercial refining steps on the rancidity measures of soybean and canola oils, Food Chem.2009;115(3):931 6. http://dx.doi.org/10.1016/j.foodchem.2009.01.035.

17. Hassan M , Mallah E, S. Shami S.M , Hassanein M.M , Detailed studies on some lipids of Silybum marianum (L.) seed oil, Grasas y. Aceites . 2007;54(4):397-402.

18. R'užǐckova G, Fojtova J, Soǔckova M, The yield and quality of milk thistle [Silybummarianum (L). Gaertn seed oil from the perspective of environment and genotype: a pilot study, Acta Fytotech Zootech . 2001;14:9.

19. Parry J, Hao Z, Luther M, Su L, Zhou K, Yu L, Characterization of cold-pressed onion, parsley, cardamom, mullein, roasted pumpkin, and milk thistle seed oils, J. Am. Oil Chem. Soc.2006;83(10):847-854

20. Fathi-Achachlouei B, Azadmard-Damirchi S, Milk thistle seed oil constituents from different varieties grown in Iran, J. Am. Oil Chem. Soc.2009;86(7):643-9. http://dx.doi.org/10.1007/s11746-009-1399-y. 